\title{
Peter Beighton Festschrift
}

In the Peter Beighton Festschrift (supplement to the June 2016 SAMJ, Vol. 106, No. 6), the following errors occurred:

Text was missing from the end of the tribute by Peter Bonafede on p. S62, the final paragraph and last two lines of which should have read: It is now 38 years since I worked in the Department of Human Genetics, UCT, and it was a most productive and enjoyable time in my practice of medicine. I have many wonderful memories and could recount numerous additional anecdotes. I can truly say that PB was a major leader in the development of the field of human genetics in SA and his influence is felt worldwide. I was very fortunate to be able to learn and work under him and am proud to have played a very small role in his department in the early days.

Thank you, Prof. Beighton.

Thank you Janet Bonafede and Caroline McCulley, MD, for critical review of the manuscript.

In the tribute by George Gericke starting on the same page, the first paragraph should have read as follows:

Who is Peter Beighton? A man's man, characterised by honesty, integrity, humility, diligence and a love of exuberant laughter; highly adventurous and of great courage, racing the death-defying Isle of Man motorcycle event; walking across the Sahara with a Taureg, recording urine osmolality along the trip; and being a military medical officer with the UN in the (then) Belgian Congo.

Paragraph 3 of the same tribute (p. S63) should have read as follows:

He had an exceptional lecturing talent, interlaced with humour. Once, at Tygerberg Hospital, where, in his last slide, an orthopaedic surgeon stood next to a man with a skeletal dysplasia, he asked, 'Is the Professor of Orthopaedics a giant, or is the patient a dwarf?'

The online version of the supplement was corrected on 31 May 2016.

S Afr Med J 2016;106(7):735. DOI:10.7196/SAMJ.2016.v106i7.11156 